\title{
JACOB Voice Chatbot Application Using Wit.ai for Providing Information in UMN
}

\author{
Steven Wijaya, Arya Wicaksana
}

\begin{abstract}
In this modern age, chatbots have been widely used as an information provider. The popularity of voice-based chatbots or voice chatbots has also increased with the presence of technologies such as Microsoft Cortana, Amazon Lex, Apple Siri, and Google Assistant. Interaction with voice chatbot is done using a voice which is more convenient than the text-based chatbots. Universitas Multimedia Nusantara (UMN) requires a tool to provide information for the Informatics joint-degree program. In this paper, a voice chatbot named JACOB is proposed. JACOB is built as a web-based application and implemented with Web Speech API. The sentences received by JACOB are translated using Wit.ai. The Jaro-Winkler distance is also applied in this research to reduce errors in identifying the user's name. This implementation has been tested successfully, and the total satisfaction score measured using End User Computing Satisfaction is $78.53 \%$.
\end{abstract}

Index Terms: JACOB, UMN, Voice Chatbot, Wit.ai.

\section{INTRODUCTION}

The term chatbot starts with the question asked by Alan Turing, which is whether or not machines could think [1]. The concept of a chatbot is to form a machine that can interact with humans and use their intelligence to answer the questions given [2], [3]. The chatbot was then developed with a number of objectives and one of them was as an information provider.

The development of chatbots will continue to go hand in hand with the development of technology and the internet. Currently, chatbots have been successfully developed into 2 types, which is text-based and voice-based [4]. In addition to chatbots that use text in their communication, voice-based virtual assistants and voice-based chatbots also have quite high popularity as for voice-based virtual assistants have been developed by several large companies, such as Microsoft's Cortana, Amazon Alexa, Apple Siri, Google Assistant, etc. [5].

Natural Language Processing (NLP) is one of the main processes behind all those voice-based chatbots. NLP is used for understanding natural language that is human language so that the machine could understand and process it. This ability supports chatbot to have intelligence and interact like humans [6]. There is an NLP / NLU service like Wit.ai

Revised Manuscript Received on September 22, 2019.

Steven Wijaya, Department of Informatics, Universitas Multimedia Nusantara, Tangerang - 15810, Indonesia.

Arya Wicaksana, Department of Informatics, Universitas Multimedia Nusantara, Tangerang - 15810, Indonesia. which can be used to extract important structured information from a sentence [7]. Wit.ai provides free services without restrictions and also has a wide range

of languages and machine learning tools [8]. Wit.ai works by extracting intent and entities from a sentence. With the intent and entities obtained from a sentence, the intent captured by the chatbot can be better and more flexible and the responses given can be more precise [9].

Universitas Multimedia Nusantara (UMN) is a private university in Indonesia that offers a joint-degree program since 2017. This program grants two degrees for the students: Computer Bachelor and Bachelor of IT. The head of UMN Informatics Department hopes that a voice chatbot could boost the joint-degree program to potential students as an information provider. With this chatbot, the head of UMN Marketing Department expects to utilize it for providing information to market the joint-degree program internationally. Thus, this paper proposes a voice chatbot that is named JACOB that could provide information regarding the joint-degree program for potential students in English.

Voice chatbot does interact directly with users by voice. The process of voice recognition is composed of two parts that are capturing and analyzing sounds [10]. However, like seeing real examples in everyday life, humans could get wrong in capturing the pronunciation of someone's name. This could also occur on voice chatbots. To reduce this error, it is necessary to implement an algorithm to examine the captured information.

The Jaro-Winkler distance which is a pattern matching algorithm is commonly used for string matching. The algorithm could match first names, last names and full names. This algorithm has good performance with a fairly short time compared to similar algorithms such as the Levensthein Distance, Damerau-Levensthein Distance, or with algorithms from phonetic encoding such as Soundex, Phonex, and Phonix [11].

The evaluation of the JACOB voice chatbot is done using End User Computing Satisfaction (EUCS). EUCS is an overall evaluation of information systems based on end-user experience in using the system [12]. This evaluation model is developed by Doll \& Torkzadeh [13] with five factors of satisfaction: content, accuracy, format, ease of use, and timeliness. By looking at the satisfaction of the user, conclusions can be drawn about whether or not the application is useful and accepted by the public. For each of the satisfaction

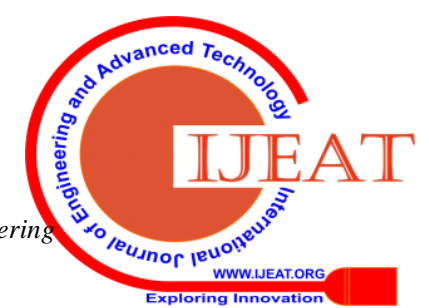


factors, there are questions given to be scored later. The answers to the questions are scored using the Likert scale. Likert scale is useful to measure the level of attitudes scientifically by weighting the choice of attitude responses that are in value [14].

\section{METHODS}

The methodology used in this work is feasibility studies, literature review, analysis and design, application development, and testing and evaluation. The feasibility study conducted was by interviewing UMN's general manager of marketing and the head of the UMN Informatics study program. The results of the interviews also obtained a list of questions and answers that were used as JACOB's knowledge base. Each question and answer is then made variations with different sentences so that it can enrich JACOB's knowledge. Questions are used to be trained using Wit.ai to generate intents and entities. While the answers are stored in the database with the corresponding intent and entities.

The literature review was conducted to obtain the knowledge base of the joint-degree program, voice chatbot, Wit.ai, Jaro-Winkler distance, and End User Computing Satisfaction (EUCS). Analysis and design are done by designing voice chatbot applications into UML diagrams and database table structures. Then the application development is done on a web base that uses the Laravel framework. The implementation of Wit.ai is done by calling HTTP request from javascript and PHP. The Web Speech API also uses javascript. In the final stage after the application is completed, black box testing is carried out on the Jaro-Winkler distance that is implemented and also evaluation of user satisfaction is carried out after using JACOB voice chatbot. Questions for EUCS evaluation follow the guidelines of the example in an existing paper [13]-[15]

The overall general design of JACOB voice chatbot application is shown in Fig. 1. Users interact with JACOB using voice. Voice is received in the browser via the Web Speech API Speech Recognition which is then generated a text. The obtained text is sent to Wit.ai to obtain intent and entities. Intents and entities can then be used to determine the answers sought from the database.

The answers obtained are converted back into voice in the browser using the Web Speech API Speech Synthesis. Interactions between JACOB voice chatbot and users are carried out alternately and gradually starting with greetings, introductions, questions, and answers, and thank you or goodbye. The image explains for one conversation from the user which actually done repeatedly in the interaction between users and JACOB. Users could use JACOB as seen in the use case diagram in Fig. 2.

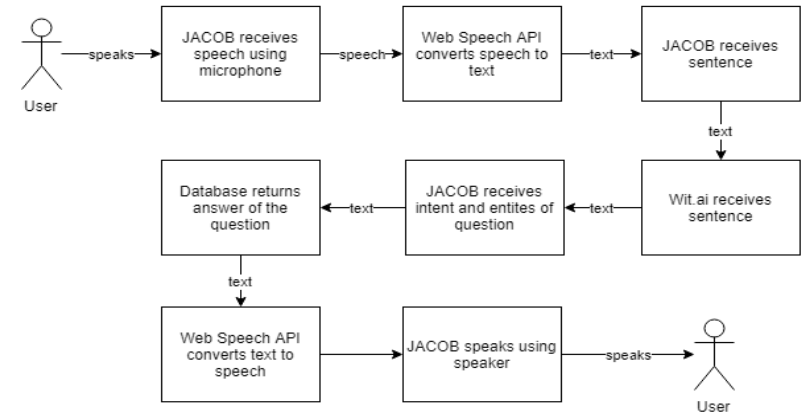

Fig. 1: General design of interaction with voice chatbot

There are two types of administrator: admin and super admin. Admin and super admin have the same ability that is able to change the basic knowledge that is owned by JACOB. This basic knowledge is seen from 3 tables that describe the relationships of intent, entities, and answers. Fig. 3. Describing the use case of admin and super admin. The advantage of super admin is that it can add a new admin to the application.

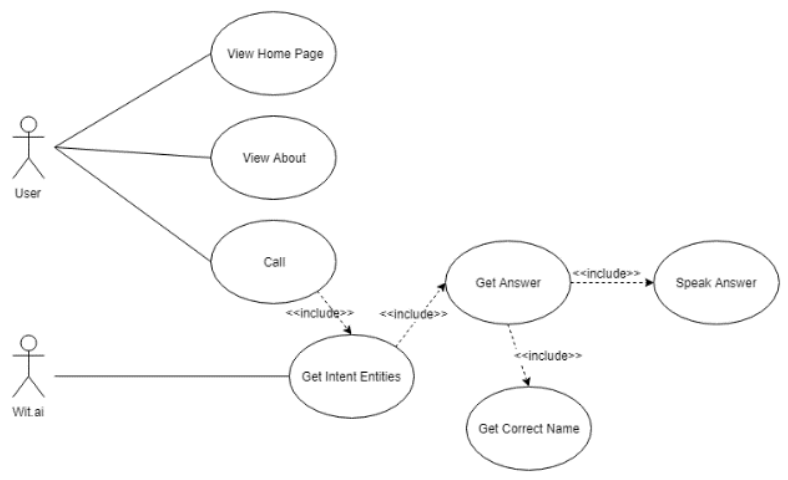

Fig. 2: JACOB use case diagram

The implementation of the Jaro-Winkler distance is placed on the use case Get Correct Name which can be seen in Fig. 2. This algorithm works based on matching and transposition of two words [16]. To calculate the value of Jaro-Winkler, it is necessary to calculate the value of Jaro in advance. The formula used to calculate these two is based on [17]. While the names used as the list of names are obtained from [18]-[20].

The JACOB voice chatbot application is designed and built on a web base so that it is easily accessible on various platforms [21]. The appearance of this application is very simple and provides enough information for users to interact. Fig. 4. is an example of a page when interacting with JACOB. The admin also has its own page to change JACOB's basic knowledge. Admin must login first to enter to the administrator page.

\section{RESULTS AND ANALYSIS}

\section{A. Implementation Testing}

This test is conducted to find out whether or not the implementation of the Jaro-Winkler distance is successful. The names received are tested by a list of names owned by JACOB. The name 
that has the largest Jaro-Winkler distance is considered as the correct name. This name is then used to address the user. Here, the implementation is tested using two test-cases.

The first test-case uses the name Sela and the results could be seen in Fig. 5. The highest distance is produced by Sella. Thus, JACOB identifies the name of the user as Sella. The manual calculations of the Jaro-Winkler distance is given in Table I.

The second test-case uses the name Kevin and the results could be seen in Fig 6. Based on the results, name Kevin produces the highest distance. Thus, the name is used by JACOB to address the user. Table II. Shows the manual calculations of the Jaro-Winkler distance.

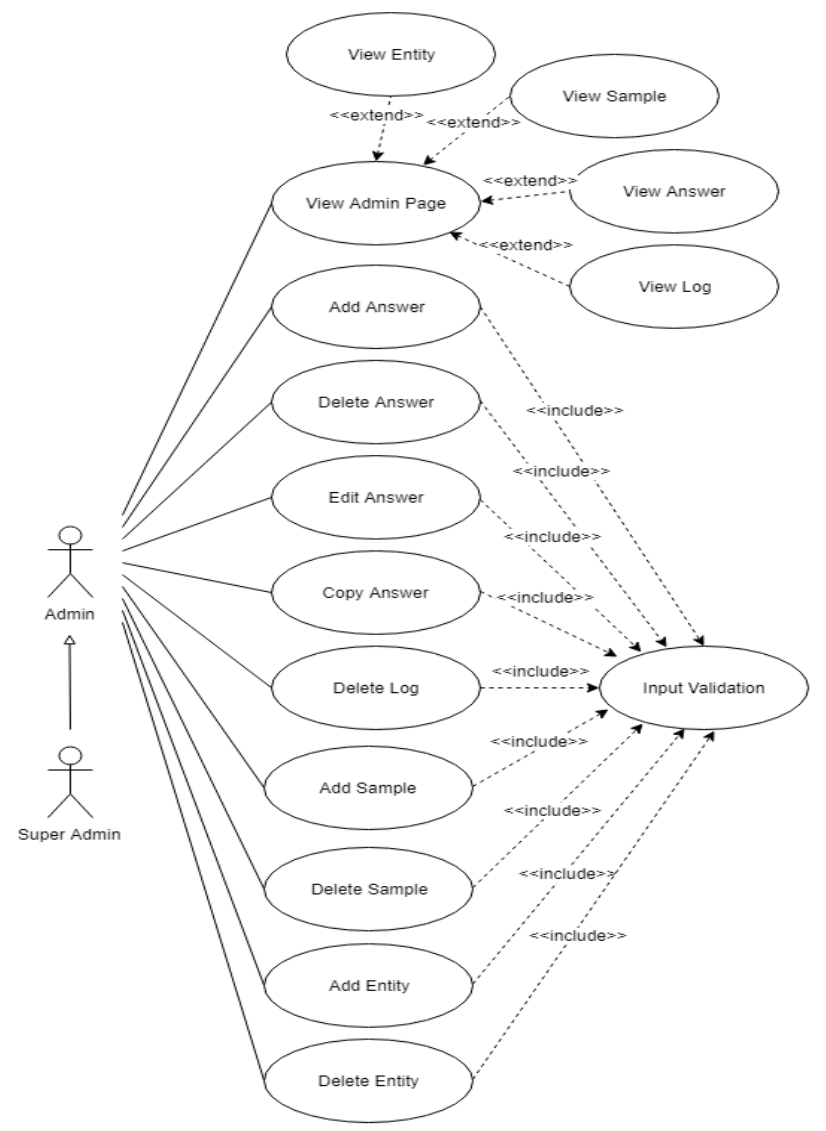

Fig. 3: Use case diagram for admin and super admin

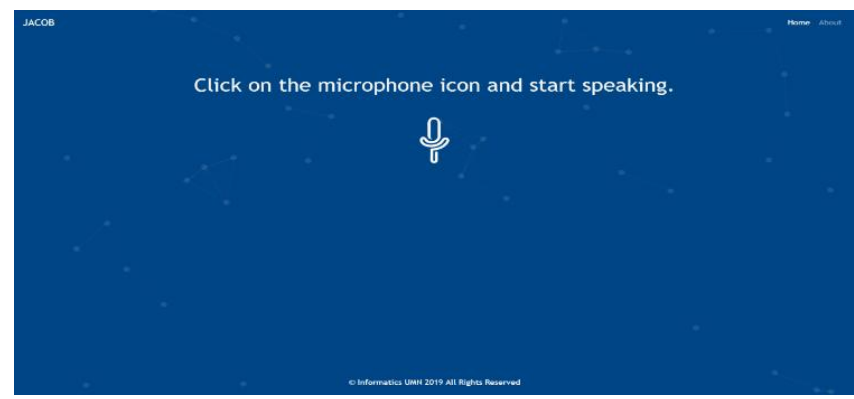

Fig. 4: User interface of JACOB voice chatbot

\section{localhost:8000/tes?nama=sela \\ $\times+$ \\ $\leftarrow \rightarrow$ C (i) localhost:8000/tes?nama=sela}

nama yang ingin diperiksa: sela

sella dengan nilai JaroWinkler $=0.95333333333333$

selma dengan nilai JaroWinkler $=0.95333333333333$

shela dengan nilai JaroWinkler $=0.94$

selian dengan nilai JaroWinkler $=0.9222222222222$

selvya dengan nilai JaroWinkler $=0.92222222222222$

Fig. 5: Jaro-Winkler test with name Sela

\section{B. Evaluation}

The total number of people who filled out the questionnaire for the EUCS evaluation are 30 people including 2 persons from the UMN Marketing Department. The questionnaire uses a 6-level Likert scale. The results of the five factors are displayed in Fig. 7. In Fig. 7, the values of each factor are $78.48 \%$ for Content, $74.45 \%$ for Accuracy, $81.95 \%$ for Format, $79.45 \%$ for Ease of Use, and $78.34 \%$ for Timeliness. The final satisfaction score is $78.53 \%$.

Based on the calculation of the final satisfaction score, it could be concluded that $78.53 \%$ of users are satisfied with the use of JACOB's voice chatbot as the information provider of the joint-degree program. The smallest value is obtained on the accuracy variable. This is influenced by the accuracy of the answers given by JACOB and the satisfaction towards the answers.

Table I. Manual calculation of Jaro-Winkler with name Sela

\begin{tabular}{|l|l|l|}
\hline Name & \multicolumn{1}{|c|}{ Steps } & \multicolumn{1}{c|}{ Result } \\
\hline \multirow{4}{*}{ sella } & $\begin{array}{l}\text { Character distance } \\
\text { measured }\end{array}$ & $0.5 * 5-1=1$ \\
\cline { 2 - 3 } & Same characters & "sela" \\
\cline { 2 - 3 } & Total of same characters & 4 \\
\cline { 2 - 3 } & Transposition & 0 \\
\cline { 2 - 3 } & Jaro distance & 0.933333333333333 \\
\cline { 2 - 3 } & Prefix length & 3 \\
\cline { 2 - 3 } selma & Jaro-Winkler distance & 0.9533333333333333 \\
\hline \multirow{5}{*}{} & $\begin{array}{l}\text { Character distance } \\
\text { measured }\end{array}$ & $0.5 * 5-1=1$ \\
\cline { 2 - 3 } & Same characters & "sela" \\
\cline { 2 - 3 } & Total of same characters & 4 \\
\cline { 2 - 3 } & Transposition & 0 \\
\cline { 2 - 3 } & Jaro distance & 0.9333333333333333 \\
\cline { 2 - 3 } & Prefix length & 3 \\
\cline { 2 - 3 } & Jaro-Winkler distance & 0.953333333333333 \\
\hline \multirow{5}{*}{ shela } & $\begin{array}{l}\text { Character distance } \\
\text { measured }\end{array}$ & $0.5 * 5-1=1$ \\
\cline { 2 - 3 } & Same characters & "sela" \\
\cline { 2 - 3 } & Total of same characters & 4 \\
\cline { 2 - 3 } & Transposition & 0 \\
\hline & Jaro distance & 0.9333333333333333 \\
\hline & Prefix length & 1 \\
\hline & Jaro-Winkler distance & 0.940000000000000 \\
\hline
\end{tabular}




\begin{tabular}{|l|l|l|}
\hline \multirow{5}{*}{ selian } & $\begin{array}{l}\text { Character distance } \\
\text { measured }\end{array}$ & $0.5 * 6-1=2$ \\
\cline { 2 - 3 } & Same characters & "sela" \\
\cline { 2 - 3 } & Total of same characters & 4 \\
\cline { 2 - 3 } & Transposition & 0 \\
\cline { 2 - 3 } & Jaro distance & 0.888888888888889 \\
\cline { 2 - 3 } & Prefix length & 3 \\
\cline { 2 - 3 } & Jaro-Winkler distance & 0.92222222222222 \\
\hline \multirow{5}{*}{} & $\begin{array}{l}\text { Character distance } \\
\text { measured }\end{array}$ & $0.5 * 6-1=2$ \\
\cline { 2 - 3 } & Same characters & "sela" \\
\cline { 2 - 3 } & Total of same characters & 4 \\
\cline { 2 - 3 } & Transposition & 0 \\
\cline { 2 - 3 } & Jaro distance & 0.888888888888889 \\
\cline { 2 - 3 } & Prefix length & 3 \\
\cline { 2 - 3 } & Jaro-Winkler distance & 0.92222222222222 \\
\hline
\end{tabular}

Table II. Manual calculation of Jaro-Winkler with name Kevin

\begin{tabular}{|c|c|c|}
\hline \multirow[b]{2}{*}{ Name } & \multirow{2}{*}{\multicolumn{2}{|c|}{ Result }} \\
\hline & & \\
\hline \multirow{7}{*}{ kevin } & $\begin{array}{l}\text { Character distance } \\
\text { measured }\end{array}$ & $0.5 * 5-1=1$ \\
\hline & Same characters & "kevin" \\
\hline & $\begin{array}{l}\text { Total of same } \\
\text { characters }\end{array}$ & 5 \\
\hline & Transposition & 0 \\
\hline & Jaro distance & 1 \\
\hline & Prefix length & 4 \\
\hline & Jaro-Winkler distance & 1 \\
\hline \multirow{7}{*}{ kevina } & $\begin{array}{l}\text { Character distance } \\
\text { measured }\end{array}$ & $0.5 * 6-1=2$ \\
\hline & Same characters & "kevin" \\
\hline & $\begin{array}{l}\text { Total of same } \\
\text { characters }\end{array}$ & 5 \\
\hline & Transposition & 0 \\
\hline & Jaro distance & 0.944444444444444 \\
\hline & Prefix length & 4 \\
\hline & Jaro-Winkler distance & 0.966666666666666 \\
\hline \multirow{7}{*}{ kevi } & $\begin{array}{l}\text { Character distance } \\
\text { measured }\end{array}$ & $0.5 * 5-1=1$ \\
\hline & Same characters & "kevi" \\
\hline & $\begin{array}{l}\text { Total of same } \\
\text { characters }\end{array}$ & 4 \\
\hline & Transposition & 0 \\
\hline & Jaro distance & 0.933333333333333 \\
\hline & Prefix length & 4 \\
\hline & Jaro-Winkler distance & 0.960000000000000 \\
\hline \multirow{7}{*}{ kelvin } & $\begin{array}{l}\text { Character distance } \\
\text { measured }\end{array}$ & $0.5 * 6-1=2$ \\
\hline & Same characters & "kevin" \\
\hline & $\begin{array}{l}\text { Total of same } \\
\text { characters }\end{array}$ & 5 \\
\hline & Transposition & 0 \\
\hline & Jaro distance & 0.944444444444444 \\
\hline & Prefix length & 2 \\
\hline & Jaro-Winkler distance & 0.955555555555555 \\
\hline \multirow[t]{2}{*}{ khevin } & $\begin{array}{l}\text { Character distance } \\
\text { measured }\end{array}$ & $0.5 * 6-1=2$ \\
\hline & Same characters & "kevin" \\
\hline
\end{tabular}

\begin{tabular}{|l|l|}
\hline $\begin{array}{l}\text { Total of same } \\
\text { characters }\end{array}$ & 5 \\
\hline Transposition & 0 \\
\hline Jaro distance & 0.944444444444444 \\
\hline Prefix length & 3 \\
\hline Jaro-Winkler distance & 0.949999999999999 \\
\hline
\end{tabular}

localhost:8000/tes?nama=kevin $\times \quad+$

$\leftarrow \quad \rightarrow$ C (1) localhost:8000/tes?nama=kevin

nama yang ingin diperiksa: kevin

kevin dengan nilai JaroWinkler $=1$

kevina dengan nilai JaroWinkler $=0.96666666666667$

kevi dengan nilai JaroWinkler $=0.96$

kelvin dengan nilai JaroWinkler $=0.95555555555556$

khevin dengan nilai JaroWinkler $=0.95$

Fig. 6: Jaro-Winkler test with name Kevin

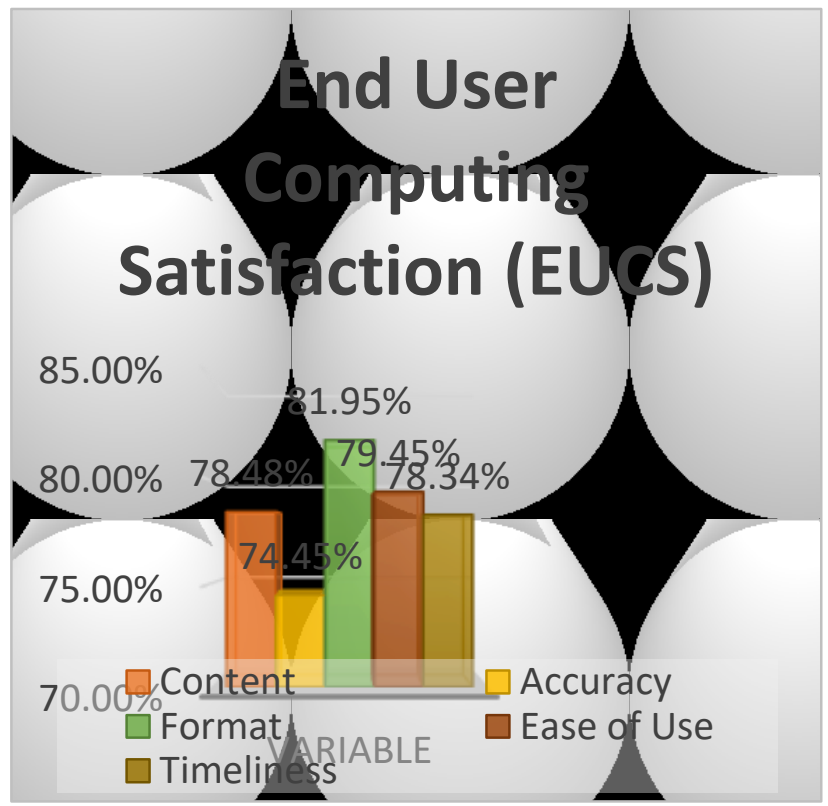

Fig. 7: JACOB End User Computing Satisfaction (EUCS) evaluation result

\section{CONCLUSION}

The JACOB voice chatbot has been successfully built as a web-based application. The voice chatbot makes use of the Jaro-Winkler distance, Web Speech API, and Wit.ai. The Web Speech API is useful as the hearing and speaking tools for JACOB. The Wit.ai is useful for understanding the context of the spoken sentences given by the users. The Jaro-Winkler distance helps to minimize the error in identifying the user's name. This is done by comparing the names given with the names in the list of names.

The evaluation of the JACOB voice chatbot using the End User Computing Satisfaction model achieves final satisfaction score of $78.53 \%$. This score is obtained from 5 factors of satisfaction (Content, Accuracy, Format, Ease of Use, and Timeliness) in the EUCS model. The questionnaire is distributed to 30 persons and the answers are scaled

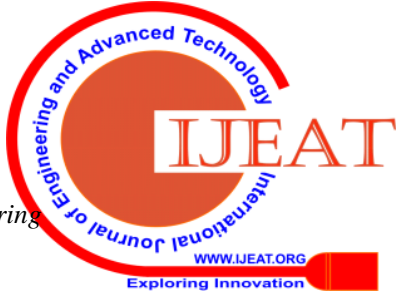


using the Likert scale.

Future work on JACOB is to implement machine learning to update the knowledge-based periodically and automatically [21]. Another work is to improve the user experience when speaking with JACOB by visualizing JACOB. Facial recognition module could also be added to enrich JACOB voice chatbot [22]. These works are intended to increase the overall satisfaction score of JACOB.

\section{ACKNOWLEDGMENTS}

I would like to thank my supervisor Arya Wicaksana for the support, guidance, and advice on this work. Besides that, I also want to thank the UMN Marketing Department and Informatics Department for assisting me in preparing the questions and answers that are useful for JACOB's knowledge base.

\section{REFERENCES}

1. J. Cahn, “CHATBOT: Architecture, Design, \& Development”, University of Pennsylvania, 2017.

2. VOICE (2018). The Evolution of Chatbot Technology [Online] Available:https://cwoodall.expressions.syr.edu/2018/04/24/the-evolution -of-chat.

3. M. Mauldin, "ChatterBots, TinyMuds, and the Turing Test: Entering the Loebner Prize Competition," Proceeding AAAI'94 Proceedings of the Twelfth AAAI National Conference on Artificial Intelligence, 1994, pp. 16-21.

4. T. Lalwani, S. Bhalotia, A. Pal, S. Bisen, and V. Rathod, "Implementation of a Chat Bot System using AI and NLP," International Journal of Innovative Research in Computer Science \& Technology (IJIRCST), vol. 6 , no. 3, 2018, pp. 26-30.

5. V. Këpuska and G. Bohouta, "Next-generation of virtual personal assistants (Microsoft Cortana, Apple Siri, Amazon Alexa and Google Home)," 2018 IEEE 8th Annual Computing and Communication Workshop and Conference (CCWC), Las Vegas, 2018, pp. 99-103.

6. C. J. Baby, F. A. Khan, and J. N. Swathi, "Home automation using IoT and a chatbot using natural language processing," International Conference on Innovations in Power and Advanced Computing Technologies, 2017, pp. 1-6.

7. D. Braun, A. H. Mendez, F. Matthes, and M. Langen, "Evaluating Natural Language Understanding Services for Conversational Question Answering Systems," Proceedings of the SIGDIAL 2017 Conference, 2017, pp. 174-185.

8. M. Canonico and L. D. Russis, "A Comparison and Critique of Natural Language Understanding Tools," CLOUD COMPUTING 2018 : The Ninth International Conference on Cloud Computing, GRIDs, and Virtualization, 2018, pp. 110-115.

9. WIT.AI (2019). Natural Language for Developers [Online]. Available: https://wit.ai.

10. J. Kacur, J. Vojtko, and G. Rozinaj, "The training of Slovak speech recognition system based on Sphinx 4 for GSM networks," Proceedings of International Symposium "EL, MAR (Electronics in Marine) focused on Mobile Multimedia”, 2007, pp. 147-150.

11. P. Christen, "A Comparison of Personal Name Matching: Techniques and Practical Issues," The Australian National University, 2006.

12. W. W. Chin and K. O. L. Matthew, "A proposed model and measurement instrument for the formation of IS satisfaction: the case of end-user computing satisfaction," Proceeding ICIS '00 Proceedings of the twenty first international conference on Information systems, 2000, pp. 553-563.

13. W. J. Doll and G. Torkzadeh, "The measurement of end-user computing satisfication," MIS Quarterly, vol. 12, no. 2, 1988, pp. 259-274.

14. A. Joshi, S. Kale, S. Chandel, and D. K. Pal, "Likert Scale: Explored and Explained," British Journal of Applied Science \& Technology, vol. 7, no. 4, 2015, pp. 396-403.

15. S. F. A. Helm, B. S. Chaparro, and S. M. Farmer, "Using the End-User Computing Satisfaction (EUCS) Instrument to Measure Satisfaction with a Web Site," Decision Sciences, vol. 36, no. 2, 2005, pp. 341-364.

16. X. D. Coster et al (2011). Mahalanobis distance, Jaro-Winkler distance and nDollar in UsiGesture [Online]. Available: https://pdfs.semanticscholar.org/1e44/d6df6c37cdadc072ffc9f9af13da62 e53d1a.pdf.
17. K. Dreßler and A. C. N. Ngomo, "On the Efficient Execution of Bounded Jaro-Winkler Distances”, Semantic Web, vol. 8, no. 2, 2016, pp. 185-197.

18. M. Kantrowitz and B. Ross (1991). List of common female names [Online]. Available: https://www.cs.cmu.edu/Groups/AI/areas/nlp/ corpora/names/female.txt.

19. M. Kantrowitz and B. Ross, "List of common male names," 1991 , Cs.cmu.edu. [Online]. Available: https://www.cs.cmu.edu/Groups/AI/ areas/nlp/corpora/names/male.txt.

20. S. J. D. Preez, M. Lall, and S. Sinha, "AN INTELLIGENT WEB-BASED VOICE CHAT BOT”, IEEE EUROCON 2009, 2009, pp. 386-391.

21. Octavany, A. Wicaksana, "CLEVEREE: an Artificial Intelligence Module for JACOB Voice Chatbot Application", International Conference and Workshop on Telecommunication, Computing, Electrical, Electronics and Control (ICW-TELKOMNIKA), submitted for publication

22. A. Archilles, A. Wicaksana, "VISION: a Convolutional Neural Network for Face Recognition on JACOB Voice Chatbot Application", International Conference and Workshop on Telecommunication, Computing, Electrical, Electronics and Control (ICW-TELKOMNIKA), submitted for publication.

\section{Authors ProfiLe}

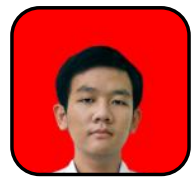

Steven Wijaya, undergraduate student in Informatics at Universitas Multimedia Nusantara. E-mail: steven.wijaya1@student.umn.ac.id.

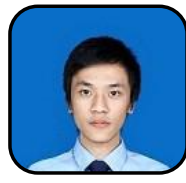

Arya Wicaksana, graduated from Universiti Tunku Abdul Rahman in VLSI Engineering (M.Eng.Sc.) and Universitas Multimedia Nusantara in Computer Science (S.Kom.). Research interests and works are: computational intelligence and quantum computing. E-mail: arya.wicaksana@umn.ac.id. 